\title{
Morfologia polínica de espécies das tribos Ipomoeeae Hallier f. e Merremieae D.F. Austin (Convolvulaceae) ocorrentes numa região de ecótono do município de Caetité, BA, Brasil ${ }^{1}$
}

\author{
Liziane Vilela Vasconcelos ${ }^{2,6}$, Marileide Dias Saba ${ }^{3}$, Maria Elizangela Ramos Junqueira ${ }^{4}$ e \\ Rosangela Simão-Bianchini ${ }^{5}$
}

Recebido: 22.07.2014; aceito: 2.02.2015

\begin{abstract}
Pollen morphology of species from tribes Ipomoeeae Hallier f. and Merremieae D.F. Austin, Convolvulaceae, occurring in an ecotonal region of the municipality of Caetité, Bahia State, Brazil). This pollen morphology study of species of the tribes Ipomoeeae and Merremieae (Convolvulaceae) aims to contribute to the knowledge of palynology of the taxa studied and to the taxonomy of the group. Ten species of Ipomoea, one of Turbina (Ipomoeeae tribe), and four species of Merremia (Merremieae tribe) occurring in the flora of the Brejinho das Ametistas, Caetité, Bahia State, Brazil were examined. The pollen grains were acetolysed, measured, described, and illustrated under light microscopy (LM) and scanning electron (SEM) microscopy. By analyzing the pollen morphology of the taxa studied, it was possible to confirm the euripollinic character of the group and to recognize two pollen types based upon the apertural type and the exine ornamentation: 1) pantoporate, echinate pollen grain; 2) 3-6-colpate, microechinate, granulate pollen grain.
\end{abstract}

Keywords: Convolvulaceae, morphology, Palynology, pollen grains

RESUMO - (Morfologia polínica de espécies das tribos Ipomoeeae Hallier f. e Merremieae D.F. Austin, Convolvulaceae, ocorrentes numa região de ecótono do município de Caetité, BA, Brasil) O estudo da morfologia polínica das espécies das tribos Ipomoeeae e Merremieae (Convolvulaceae) tem como finalidade contribuir com a ampliação do conhecimento palinológico dos táxons estudados e subsidiar a taxonomia do grupo. Foram examinados os grãos de pólen de 10 espécies de Ipomoea, uma de Turbina (tribo Ipomoeeae) e quatro de Merremia (tribo Merremieae) ocorrentes na flora de Brejinho das Ametistas, Caetité, BA, Brasil. Os grãos de pólen foram acetolisados, mensurados, descritos e ilustrados sob microscopia de luz (ML) e eletrônica de varredura (MEV). Mediante a análise da morfologia polínica dos táxons estudados, foi possível confirmar o caráter euripolínico do grupo e reconhecer dois tipos polínicos com base no tipo apertural e na ornamentação da exina: Tipo 1. grãos de pólen pantoporados, equinados; Tipo 2. grãos de pólen 3-6-colpados, microequinados, granulados. Palavras-chave: Convolvulaceae, grãos de pólen, morfologia, Palinologia

\section{Introdução}

A família Convolvulaceae Juss. apresenta distribuição cosmopolita (Souza \& Lorenzi 2012), sendo bem representada em regiões tropicais e com predomínio em áreas abertas como cerrado e caatinga. É uma das principais famílias com espécies endêmicas na caatinga (Junqueira \& Simão-Bianchini 2006). Possui 55 gêneros com 1.930 espécies (Judd et al.
2009); para o Brasil, são citados cerca de 21 gêneros e 380 espécies (Simão-Bianchini et al. 2014). Nas últimas décadas, destacaram-se os estudos moleculares, que buscaram resolver os relacionamentos filogenéticos dentro do grupo (Mcdonald \& Mabrey 1992, Miller et al. 1999, Manos et al. 2001, Stefanović et al. 2002, 2003, Stefanović \& Olmstead 2004).

Uma nova classificação baseada em dados moleculares (sequências dos genomas nucleares, de

1. Parte do Trabalho de Conclusão de Curso da primeira Autora, Universidade do Estado da Bahia, Caetité, BA, Brasil

2. Universidade Estadual de Feira de Santana, Departamento de Ciências Biológicas, Av. Transnordestina s.n., 44036-900 Feira de Santana, BA, Brasil

3. Universidade do Estado da Bahia, Departamento de Educação, Campus VII, Rodovia Lomanto Júnior s/n, BR 407, Km 127, 48970-000 Senhor do Bonfim, BA, Brasil

4. Universidade do Estado da Bahia, Departamento de Educação, Campus XI, Avenida Álvaro Augusto s/n, Bairro Rodoviária, $48700-971$ Serrinha, BA, Brasil

5. Instituto de Botânica, São Paulo, 68041, 04045-972 São Paulo, SP, Brasil

6. Autor para correspondência: lizianevilela@gmail.com 
cloroplasto e de mitocôndria) e morfológicos (p.ex., presença ou ausência de hábito parasítico, venação foliar, número e comprimento dos estiletes, formato do estigma, tipo e deiscência dos frutos e características polínicas - tipo apertural e ornamentação da exina) foi proposta por Stefanović et al. (2003), reconhecendo para a família 12 tribos: Ipomoeeae s.l., Merremieae, Convolvuleae, Aniseieae, Cuscuteae, Jacquemontieae, Maripeae, Cresseae s.l., Dichondreae s.l., Erycibeae, Cardiochlamyeae e Humbertieae.

Palinologicamente, Convolvulaceae é considerada euripolínica, apresentando grande variabilidade de caracteres polínicos, principalmente quanto ao tipo apertural e à ornamentação da exina (Erdtman 1952, Sengupta 1972), permitindo assim a utilização de tais caracteres para o reconhecimento dos táxons (Hallier 1893, Lewis \& Oliver 1965, Ferguson et al. 1977, Melhem \& Corrêa 1987, Tellería \& Daners 2003).

A morfologia polínica, como ferramenta para esclarecimento nas questões taxonômicas dos gêneros pertencentes às tribos Ipomoeeae e Merremieae, foi abordada por vários autores, como Hallier (1893), Erdtman (1952), Sengupta (1972), Ferguson et al. (1977), Pedraza (1983) e Tellería \& Daners (2003). Além destes, outros autores estudaram a morfologia polínica da família Convolvulaceae: Laguardia (1961), Lewis \& Oliver (1965), Vij \& Sachdeva (1974), Melhem \& Corrêa (1987), Machado \& Melhem (1987), Araújo et al. (2000), Leite et al. (2005) e Vital et al. (2008).

Entre os trabalhos brasileiros destacam-se os de Andrade \& Miranda (1986), Machado \& Melhem (1987) e Melhem \& Corrêa (1987), que descreveram a morfologia polínica de espécies de Ipomoea com base na distribuição das aberturas e dos espinhos. Vital et al. (2008), analisaram as espécies pertencentes a cinco gêneros das Convolvulaceae ocorrentes no Parque Nacional do Catimbau, Estado de Pernambuco, reconhecendo os dois grupos já estabelecidos por Hallier (1893) com base na ornamentação da exina: Echinoconieae e Psiloconieae.

Araújo et al. (2000) analisaram para o Estado da Bahia os grãos de pólen de 24 espécies pertencentes a 10 gêneros, incluindo sete espécies dos gêneros Ipomoea, Merremia e Turbina, as quais foram descritas e enquadradas em dois tipos polínicos: Tipo I - grãos de pólen 3- colpados e Tipo V - grãos de pólen pantoporados com espinhos longos e pontiagudos, e apresentaram uma chave polínica. O principal estudo sobre o gênero Merremia no Estado da Bahia foi realizado por Leite et al. (2005), que analisaram a morfologia polínica de nove espécies sob microscopia de luz e eletrônica de varredura, utilizando os dados para a melhor delimitação taxonômica das espécies estudadas.

Observando a diversidade e a importância palinológica para a taxonomia de Convolvulaceae, o presente trabalho foi desenvolvido com espécies ocorrentes no distrito de Brejinho das Ametistas, município de Caetité, Estado da Bahia. Com um relevo de Superfícies de Gerais do Planalto do Espinhaço, Patamares Orientais e Ocidentais do Espinhaço, e Pediplano Sertanejo, o município apresenta um clima seco a subúmido e semiárido, caracterizado por apresentar chuvas escassas e mal distribuídas ao longo do ano (SEI 2012). A diversidade vegetacional é grande, principalmente por estar localizado em uma região ecotonal (região de transição vegetacional) complexa, composta por cerrado e caatinga (Queiroz et al. 2006).

Dessa forma, objetivou-se analisar e caracterizar palinologicamente as espécies das tribos Ipomoeeae e Merremieae ocorrentes numa área de ecótono do município de Caetité, procurando contribuir com o estudo da família Convolvulaceae para a flora do Estado da Bahia, através do reconhecimento dos padrões de morfologia polínica de algumas espécies destas tribos.

\section{Material e métodos}

O material polinífero para processamento palinológico foi obtido principalmente de duplicatas ou exsicatas depositadas no Herbário HUNEB coleção Caetité, e oriundo das expedições realizadas no distrito de Brejinho das Ametistas localizado a uma distância de $24 \mathrm{~km}$ da sede do município de Caetité. Além disso, também foram obtidos materiais dos principais Herbários da Bahia: ALCB, CEPEC, HRB, HUEFS, SP e SPF, siglas conforme Thiers (2012).

Para análise sob microscopia de luz (ML), o material polinífero foi acetolisado (Erdtman 1960), montado entre lâminas e lamínulas com gelatina glicerinada e selado com parafina fundida. Após análises quantitativa e qualitativa, as lâminas foram incluídas na Palinoteca do Laboratório de Estudos Palinológicos da Universidade do Estado da Bahia Campus VI.

Para as espécies do gênero Merremia Dennst. ex Endl., as mensurações dos principais parâmetros morfométricos (diâmetro polar, diâmetro equatorial e diâmetro equatorial em vista polar) foram feitas sempre que possível em 25 grãos de pólen tomados 
aleatoriamente. Os demais parâmetros (lado do apocolpo, diâmetro das aberturas e espessura da exina), foram mensurados em 10 grãos de pólen tomados ao acaso (Salgado-Labouriau 1973).

Nos grãos de pólen apolares das espécies dos gêneros Ipomoea L. e Turbina Raf., as medidas do diâmetro único foram tomadas excluindo os espinhos. As mensurações da exina foram realizadas na região interespinal. O número de espinhos foi calculado baseando-se na fórmula proposta por Hanks \& Fryxell (1979):

$\left[\mathrm{N}^{\circ}\right.$ de espinhos $=\pi$. (diâmetro equatorial / distância interespinal $)^{2}$ ]

Nos grãos de pólen pantoaperturados com poucas aberturas, 7-20, as mesmas foram contadas; enquanto que nos grãos de pólen com mais de 30 aberturas, esse número foi estimado com base no "método $1 / 3$ " proposto por Hoen \& Punt (1989). Em microscopia óptica, o número de poros foi contado sobre um dos lados até o limite da nexina, correspondendo à $1 / 3$ do número total (1/3 é considerado para o outro lado e $1 / 3$ está presente na região do contorno dos grãos de pólen).

Os resultados quantitativos foram submetidos à análise estatística, calculando-se a média aritmética $(\overline{\mathrm{x}})$, o desvio padrão da amostra (S) e o desvio padrão da média $(S \bar{x})$ para as mensurações dos parâmetros polínicos com tamanho amostral igual a 25. Para as medidas dos demais caracteres, como o lado do apocolpo (LA), aberturas e exina, apenas a média aritmética foi calculada.

Para análise em microscopia eletrônica de varredura (MEV), os grãos de pólen foram previamente acetolisados e submetidos à série hidroetanólica ascendente $(50 \%, 70 \%, 90 \%$ e $100 \%)$. A solução contendo os grãos de pólen foi gotejada diretamente sobre um porta-espécime ("stub"), e após total secagem, foram metalizados por evaporação de ouro em alto vácuo para posterior análise.

Os caracteres morfopolínicos das espécies foram ilustrados através de fotomicrografias obtidas do fotomicroscópio Zeiss Primo Star do Laboratório de Estudos Palinológicos da Universidade do Estado da Bahia- Campus VI, e as eletromicrografias obtidas em microscópio eletrônico de varredura LEO 1430 VP - Zeiss, do Departamento de Ciências Biológicas da Universidade Estadual de Feira de Santana.

A terminologia adotada para as descrições polínicas foi baseada em Punt et al. (2007).

\section{Resultados e Discussão}

A partir do estudo polínico das 15 espécies de Convolvulaceae ocorrentes na área de estudo, foi possível estabelecer dois tipos polínicos com base no tipo apertural e ornamentação da exina: Tipo I. Grãos de pólen pantoporados, equinados (tribo Ipomoeeae); Tipo II. Grãos de pólen 3-6- colpados, microequinados, granulados (tribo Merremieae).

A tabela 1 trata-se da sinopse dos caracteres morfopolínicos e as tabelas 2 e 3 dos caracteres morfométricos dos grãos de pólen das espécies estudadas.

\section{Tipo I. Grãos de pólen pantoporados, equinados}

Tribo Ipomoeeae Hallier f.

\section{Ipomoea L.}

\section{Ipomoea amnicola Morong.}

Figuras 1-2

Grãos de pólen mônades, grandes, esferoidais, apolares; pantoporados, ca. 91 poros circulares, sem ânulo. Exina tectada, equinada, perfurada. Espinhos mamilóides, Igualmente não precisas usar parênteses ca. 80, ápice arredondado, base larga e lados côncavos, levemente constrictos na região mediana, arranjados ao redor dos poros e localizados sobre uma região da sexina de espessura igual à da região adjacente; nexina mais espessa que a sexina.

Material examinado: BRASIL. BAHIA: Caetité, Brejinho das Ametistas, 29-IV-2008, Vasconcelos et al. 64 (HUNEB, SP).

\section{Ipomoea bahiensis Willd. ex Roem. \& Schult.} Figuras 3-4

Grãos de pólen mônades, grandes, esferoidais, apolares; pantoporados, ca. 122 poros circulares e sem ânulo. Exina tectada, equinada, granulada, com grânulos, alguns fundidos, distribuídos de forma heterogênea por toda a superfície do grão de pólen. Espinhos coniformes, ca. 143, com ápice agudo, base larga e lados retos, localizados sobre região da sexina mais espessa que a da região adjacente. Nexina mais espessa que a sexina.

Material examinado: BRASIL. BAHIA: Caetité, Brejinho das Ametistas, 13-V-2009, Vasconcelos et al. 245 (HUNEB, SP). 


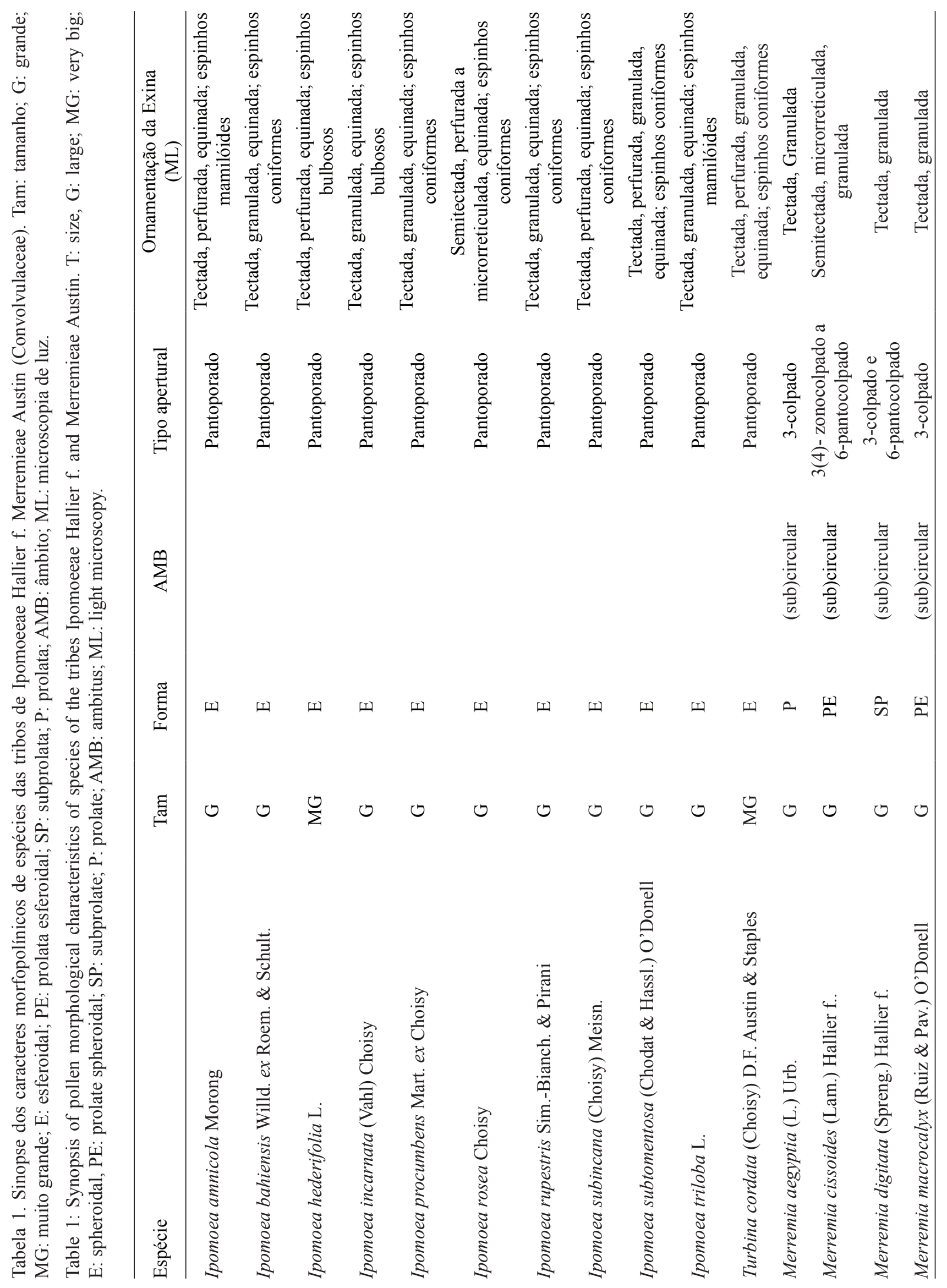


Vasconcelos et al.: Morfologia polínica de espécies de Convolvulaceae ocorrentes em Caetité, BA 257

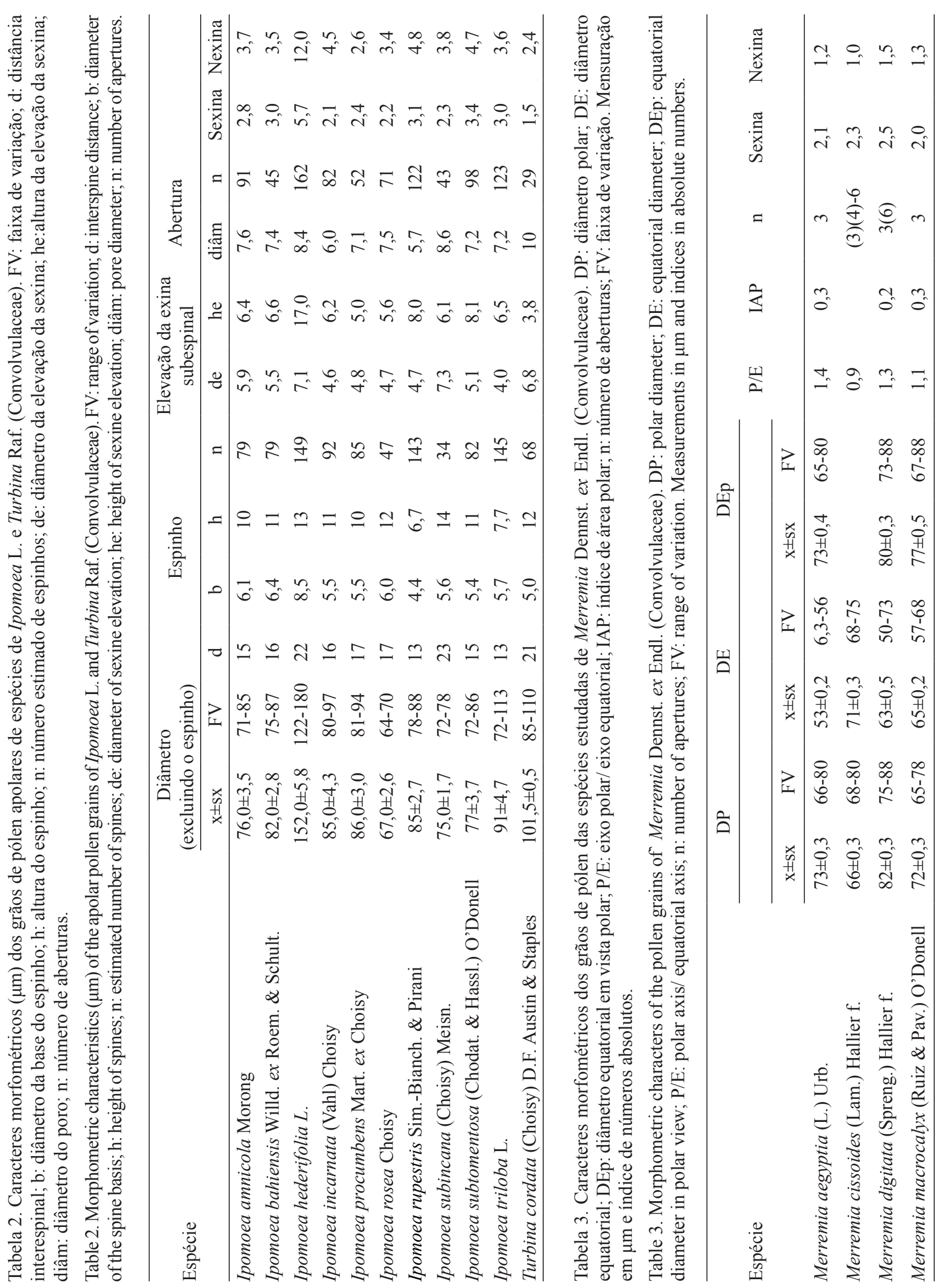



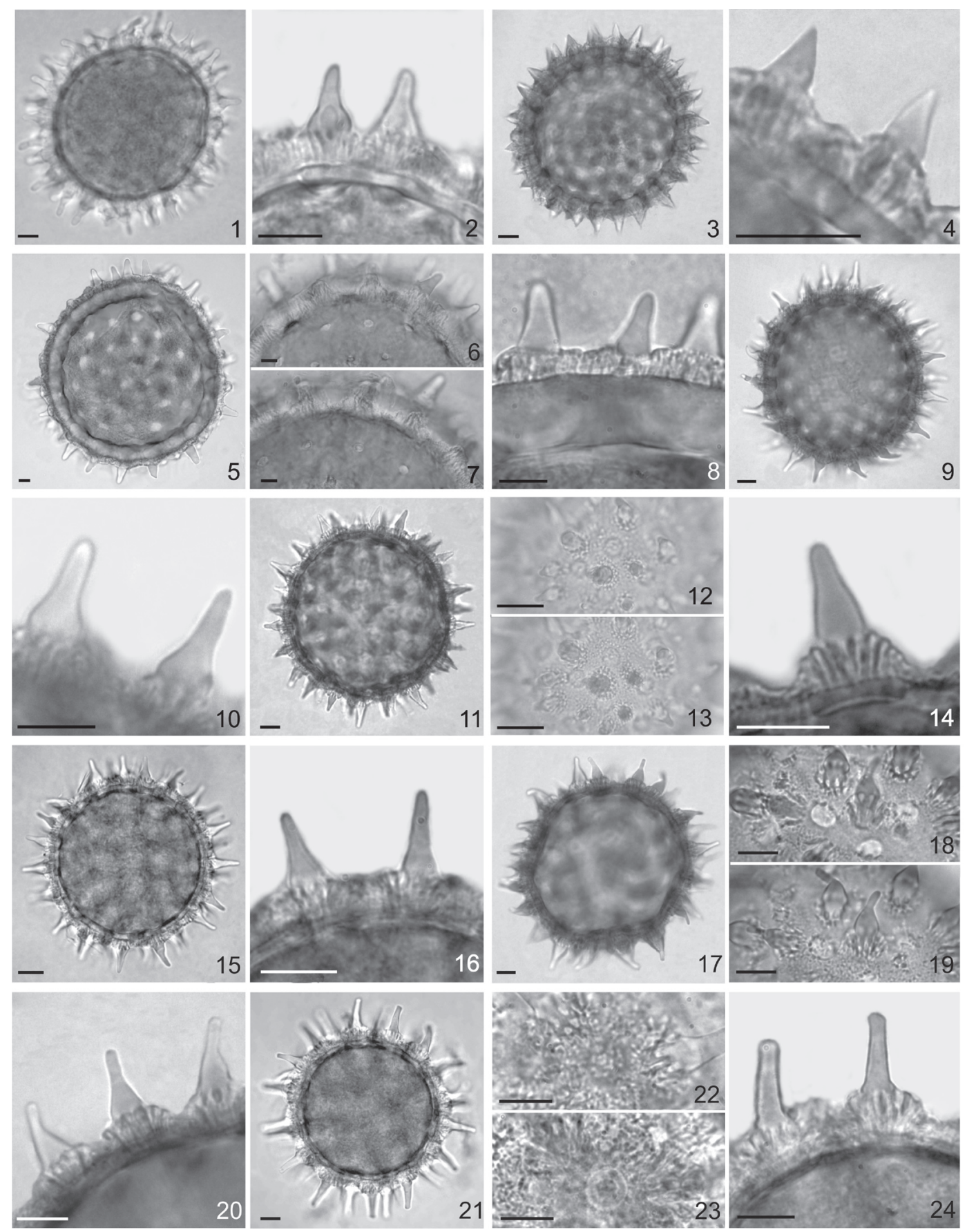

Figuras 1-24. Grãos de pólen de espécies de Ipomoea L. 1-2. I. amnicola Morong. 1. Corte óptico, vista geral. 2. Detalhe dos espinhos. 3-4. I. bahiensis Willd. ex Roem. \& Schult. 3. Corte óptico, vista geral. 4. Detalhe dos espinhos. 5-8. I. hederifolia L. 5. Corte óptico, vista geral. 6-7. Análise de L.O. 8. Detalhe dos espinhos. 9-10. I. incarnata (Vahl) Choisy. 9. Corte óptico, vista geral. 10. Detalhe dos espinhos. 11-14. I. procumbens Mart. ex Choisy. 11. Corte óptico, vista geral. 12-13. Análise de L.O. 14. Detalhe do espinho. 15-16. I. rosea Choisy. 15. Corte óptico, vista geral. 16. Detalhe dos espinhos. 17-20. I. rupestris Sim.-Bianch. \& Pirani. 17. Corte óptico, vista geral. 18-19. Análise de L.O. 20. Detalhe dos espinhos. 21-24. I. subincana (Choisy) Meisn. 21. Corte óptico, vista geral. 22-23. Análise de L.O. 24. Detalhe dos espinhos. (Escala $=10 \mu \mathrm{m})$.

Figure 1-24. Pollen grains of Ipomoea L. species. 1-2. I. amnicola Morong. 1. General view, optical section. 2. Spine. 3-4. I. bahiensis Willd. ex Roem. \& Schult. 3. General view, optical section. 4. Spine. 5-7. I. hederifolia L. 5. General view, optical section. 6-7. L.O. analysis. 8. Spine. 9-10. I. incarnata (Vahl) Choisy. 9. General view, optical section; 10. Spine. 11-14. I. procumbens Mart. ex Choisy. 11. General view, optical section. 12-13. L.O. analysis. 14. Spine. 15-16 I. rosea Choisy. 15. General view, optical section. 16. Spine. 17-20. I. rupestris Sim.-Bianch. \& Pirani. 17. General view, optical section. 18-19. L.O. analysis. 20. Spine. 21-24. I. subincana (Choisy) Meisn. 21. General view, optical section. 22-23. L.O. analysis. 24. Spine. (Scale $=10 \mu \mathrm{m})$. 


\section{Ipomoea hederifolia L.}

Figuras 5-8

Grãos de pólen mônades, muito grandes, esferoidais, apolares; pantoporados, ca. 162 poros circulares a levemente alongados, com ânulo, com distribuição equidistante pela superfície do grão de pólen. Exina tectada, equinada, perfurada, ca. 150 espinhos bulbosos e com ápice arredondado, base larga e lados levemente côncavos. Sexina com espessura homogênea por toda a superfície do grão, não se diferenciando na região subespinal; nexina mais espessa que a sexina.

Material examinado: BRASIL. BAHIA: Caetité, Brejinho das Ametistas, 29-IV-2008, Vasconcelos et al. 68 (HUNEB, SP).

\section{Ipomoea incarnata (Vahl) Choisy}

Figuras 9-10

Grãos de pólen mônades, grandes, esferoidais, apolares; pantoporados, ca. 82 poros circulares, sem ânulo. Exina tectada, equinada, granulada, ca. 92 espinhos bulbosos e com ápice arredondado e lados côncavos, localizados sobre região da sexina mais espessa que a da região adjacente. Nexina mais espessa que a sexina.

Material examinado: BRASIL. BAHIA: Caetité, Brejinho das Ametistas, 29-IV-2001, Correia et al. 28 (ALCB).

\section{Ipomoea procumbens Mart. ex Choisy}

Figuras 11-14

Grãos de pólen mônades, grandes, esferoidais, apolares; pantoporados, ca. 52 poros circulares, sem ânulo. Exina tectada, equinada, granulada, com grânulos distribuídos de forma heterogênea por todo grão de pólen. Espinhos coniformes, ca. 85, com ápice arredondado, base larga e lados côncavos, distribuídos por toda superfície do grão de pólen e localizados sobre região da sexina mais espessa que a da região adjacente. Nexina mais espessa que a sexina.

Material examinado: BRASIL. BAHIA: Caetité, Brejinho das Ametistas, 22-I-2008, Vasconcelos et al. 197 (HUNEB).

\section{Ipomoea rosea Choisy}

Figuras 15-16

Grãos de pólen mônades, grandes, esferoidais, apolares; pantoporados, ca. 71 poros circulares, com ânulo, distribuídos regularmente por toda a superfície do grão. Exina semitectada, perfurada a microrreticulada, equinada. Espinhos coniformes, ca. 50, com ápice arredondado, base larga e lados côncavos, densamente distribuídos por toda superfície do grão de pólen e localizados sobre região da sexina mais espessa que a da região adjacente. Nexina mais espessa que a sexina.

Material examinado: BRASIL. BAhIA: Caetité, Brejinho das Ametistas, 18-III-2008, Vasconcelos et al. 55 (HUNEB, SP).

7. Ipomoea rupestris Sim.-Bianch. \& Pirani Figuras 17-20

Grãos de pólen mônades, grandes, esferoidais, apolares; pantoporados, ca. 45 poros circulares, sem ânulo. Exina tectada, equinada, granulada, com grânulos esparsos por toda a superfície do grão de pólen. Espinhos coniformes, ca. 80, com ápice arredondado, base larga e lados constrictos na região mediana, localizados sobre região da sexina mais espessa que a da região adjacente. Nexina mais espessa que a sexina.

Material examinado: BRASIL. BAhIA: Caetité, Brejinho das Ametistas, 28-IV-2008, Anjos et al. 4 (ALCB).

\section{Ipomoea subincana (Choisy) Meisn.}

Figuras 21-24

Grãos de pólen mônades, grandes, esferoidais, apolares; pantoporados, ca. 43 poros grandes e circulares, com ânulo. Exina tectada, equinada, perfurada. Espinhos coniformes, ca. 34, longos, com ápice arredondado a achatados, base larga e lados planos, localizados sobre região da sexina mais espessa que a da região adjacente. Nexina mais espessa que a sexina.

Material examinado: BRASIL. BAhIA: Caetité, Brejinho das Ametistas, 18-III-2008, Vasconcelos et al. 53 (HUNEB, SP).

\section{Ipomoea subtomentosa (Chodat \& Hass1.) O’Donell} Figuras 25-26

Grãos de pólen mônades, grandes, esferoidais, apolares; pantoporados, ca. 100 poros circulares sem ânulo. Exina tectada, equinada, perfurada, granulada. Espinhos coniformes, ca. 82, com ápice agudo, base larga e lados retos, localizados sobre região da sexina mais espessa que a da região adjacente. Nexina mais espessa que a sexina. 

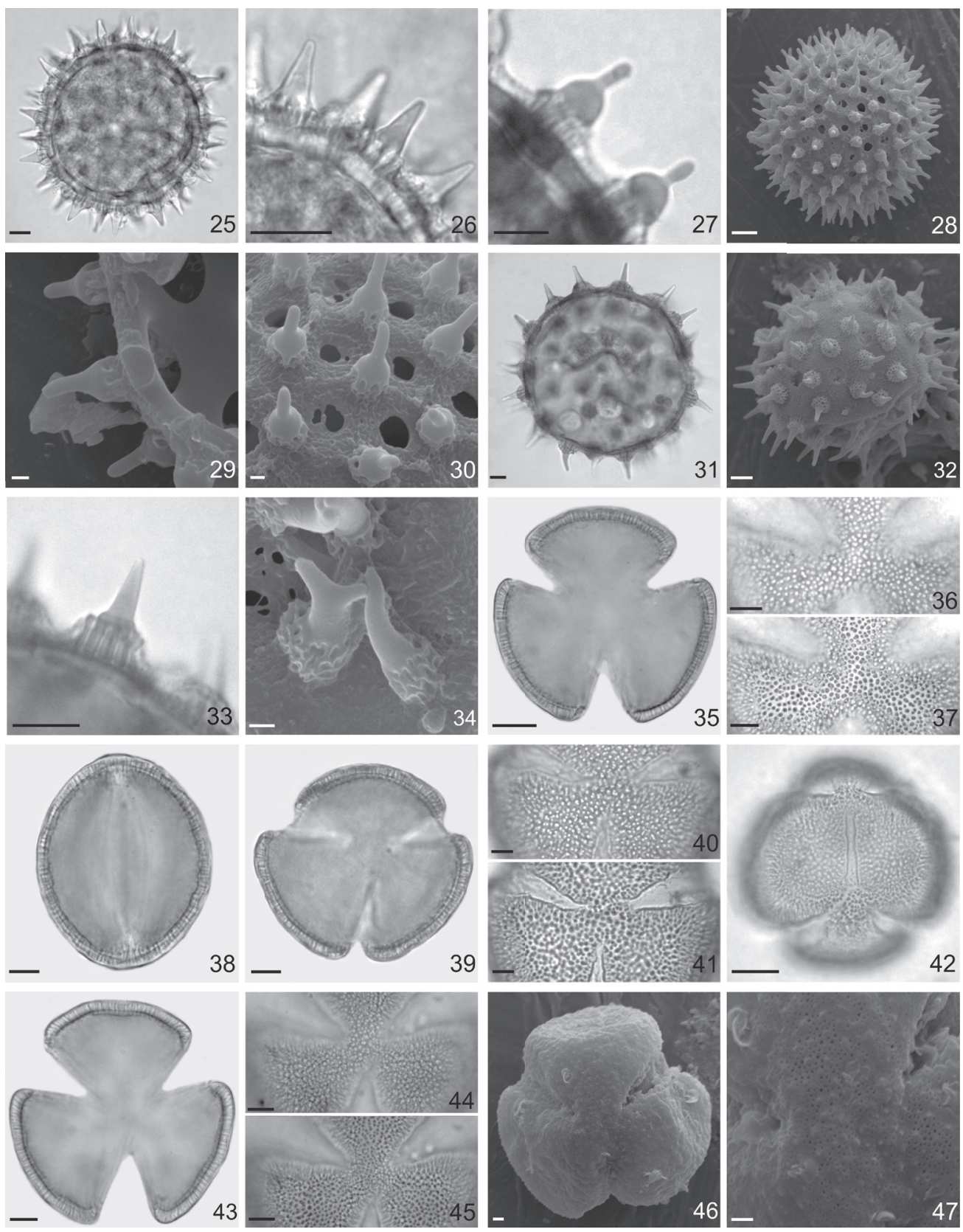

Figuras 25-47. Grãos de pólen de espécies de Ipomoea L., Turbina Raf. e Merremia Dennst. 25-26. Ipomoea subtomentosa (Chodat \& Hassl.) O’Donell. 25. Corte óptico, vista geral. 26. Detalhe dos espinhos. 27-30 I. triloba L. 27. Detalhe dos espinhos. 28. Vista geral (MEV). 29. Detalhe dos espinhos em grão de pólen quebrado (MEV). 30. Detalhe da superfície (MEV). 31-34 Turbina cordata (Choisy) D.F. Austin \& G. Staples. 31. Corte óptico, vista geral. 32. Vista geral (MEV). 33. Detalhe dos espinhos. 34. Detalhe da superfície e espinhos (MEV). 35-38. Merremia aegyptia (L.) Urban. 35. Corte óptico, vista polar. 36-37. Análise de L.O. 38. Corte óptico, vista equatorial. 39-42. M. cissoides (Lam.) Hallier f. 39. Corte óptico, vista polar. 40-41. Análise de L.O. 42. Corte óptico, vista geral, e detalhe das aberturas. 43-45. M. digitata (Spreng.) Hallier f. 43. Corte óptico, vista polar. 44-45. Análise de L.O. 46-47. M. macrocalyx (Ruiz \& Pav.) O'Donell. 46. Vista geral (MEV). 47. Detalhe da superfície (MEV). (Escala = $10 \mu \mathrm{m}$ ML; $2 \mu \mathrm{m} \mathrm{MEV).}$

Figure 25-47. Pollen grains of Ipomoea L. Turbina Raf. and Merremia Dennst. ex Endl. species. 25-26 Ipomoea subtomentosa (Chodat \& Hassl.) O’Donell. 25. General view, optical section. 26. Spine. 27-30 I. triloba L. 27. Spine. 28. General view (SEM). 29. Detail of spine in broken pollen grain (SEM). 30. Surface detail (SEM). 31-34. Turbina cordata (Choisy) Austin \& Staples. 31. General view, optical section. 32. General view (SEM). 33. Spine (SEM). 34. Surface detail and spine (SEM). 35-38. Merremia aegyptia (L.) Urban. 35. Polar view, optical section. 36-37. L.O. analysis. 38. Equatorial view, optical section. 39-42. M. cissoides (Lam.) Hallier f. 39. Polar view, optical section. 40-41. L.O. analysis. 42. General view, optical section and detail of the aperture. 43-45 M. digitata (Spreng.) Hallier f. 43. Polar view, optical section. 44-45 L.O. analysis. 46-47. M. macrocalyx (Ruiz \& Pav.) O’Donell. 46. General view (SEM). 47. Surface detail (SEM). (Scale $=10 \mu \mathrm{m}$ ML; $2 \mu \mathrm{m}$ MEV. 
Material examinado: BRASIL. BAHIA: Caetité, Brejinho das Ametistas, 29-IV-2008, Vasconcelos et al. 69 (HUNEB, SP).

\section{Ipomoea triloba L.}

Figuras 27-30

Grãos de pólen mônades, grandes, esferoidais, apolares; pantoporados, ca. 115-123 poros circulares, sem ânulo, membrana apertural psilada. Exina tectada, equinada, granulada, sob MEV, o teto apresentou elementos de ornamentação com forma irregular semelhantes a microrretículo, na região interespinal. Espinhos mamilóides, 125-145, com ápice arredondado, base larga e lados côncavos, densamente distribuídos por toda superfície do grão de pólen e localizados sobre região da sexina mais espessa que a da região adjacente; nexina mais espessa que a sexina.

Material examinado: BRASIL. BAHIA: Caetité, Brejinho das Ametistas, 29-IV-2008, Vasconcelos et al. 73 (HUNEB, SP).

Dentre os espécimes analisados, I. hederifolia apresentou os maiores grãos de pólen, variando de 122-180 $\mu \mathrm{m}$, muito grandes, e os demais permaneceram na classe grandes (tabela 2).

Quanto ao tipo apertural, os grãos de pólen das espécies analisadas caracterizaram-se como pantoporados, com o número de aberturas variando de 43-162, sendo observados ânulos em alguns grãos de pólen (figuras 6, 7, 22 e 23). Opérculos foram observados por Sengupta (1972) e Pedraza (1983). No presente trabalho foram visualizados vestígios de opérculos, entretanto, não foram confirmados em nenhum dos grãos de pólen analisados após a acetólise.

Erdtman (1952) caracterizou o tipo polínico Ipomoea pelos grãos de pólen pantoporados, equinados, que é corroborado pelo presente trabalho e vários outros encontrados na literatura (Laguardia 1961, Sengupta 1972, Vij \& Sachdeva 1974, Pedraza 1983, Andrade \& Miranda 1986, Machado \& Melhem 1987, Melhem \& Corrêa 1987, Hsiao \& Kuoh 1995, Araújo et al. 2000, Tellería \& Daners 2003, Vital et al. 2008, Rajukar et al. 2011).

Sob ML, a ornamentação da exina apresentou-se equinada, granulada ou perfurada. Os espinhos apresentaram variação quanto ao número, 34-150, altura 7-14 $\mu \mathrm{m}$, sendo os mais altos encontrados nas espécies de I. hederifolia $(13 \mu \mathrm{m})$ e $I$. subincana $(14 \mu \mathrm{m})$, e principalmente quanto à forma: bulbosos em I. hederifolia e I. incarnata (figuras 8 e 10); coniformes em I. bahiensis, I. procumbens, I. rosea,
I. rupestris, I. subincana e I. subtomentosa (figuras 4, 14, 16, 20, 24 e 26); e mamilóides em I. amnicola e I. triloba (figuras 2, 27, 29 e 30)

A nexina apresentou-se em todas as espécies aqui analisadas com espessura maior que a sexina. Com exceção de $I$. hederifolia (figura 8), a sexina na base dos espinhos apresentou-se mais espessa, formando elevações.

Outros elementos de ornamentação foram descritos para espécie I. subincana por Andrade \& Miranda (1986) e Vital et al. (2008). Báculos grandes e espessos por Andrade \& Miranda (1986), sob ML, e retículo homobrocado e orbículos por Vital et al. (2008), sob MEV. Tais caracteres não foram visualizados no presente estudo tanto sob ML, quanto sob MEV.

Sengupta (1972), Pedraza (1983) e Hsiao \& Kuoh (1995) e Tellería \& Daners (2003) classificaram as espécies do gênero Ipomoea em tipos e subtipos de acordo com a forma, disposição e número de espinhos em relação ao poro, e à ornamentação da sexina. No presente estudo, tais caracteres foram importantes para a delimitação de grupos.

A espécie Ipomoea triloba foi aqui descrita com grãos de pólen com espinhos mamilóides, com ápice arredondado e de base larga (figuras 27, 29 e 30), Laguardia (1961), descrevendo a mesma espécie caracterizou os espinhos como cones truncados.

Os dados encontrados no trabalho de Vij \& Sachdeva (1974) para Ipomoea hederifolia são, em sua maioria, corroborados pelo presente trabalho. Entretanto, os dados obtidos por Sengupta (1972), que inclui essa espécie no tipo polínico pantoporado, grupo I do seu trabalho, indicando, além de espinhos, retículo como elemento de ornamentação; assim como os dados obtidos por Machado \& Melhem (1987), que descreveram os espinhos como cônicos, situados sobre arestas, não são concordantes com os dados aqui apresentados.

Para Araújo et al. (2000), as espécies analisadas do gênero podem ser separadas a partir do tamanho espinal e ornamentação de exina. Os autores observaram membrana apertural granulada, para as espécies analisadas. No presente estudo foram observadas membranas aperturais, contudo, sem grânulos.

Tellería \& Daners (2003) agruparam as espécies de Ipomoea em um tipo polínico caracterizado por grãos de pólen com exina semitectada, equinada ou gemada, microequinada-microrreticulada, exclusivamente pantoporados. A espécie I. amnicola aqui descrita pelas autoras, apresentou grãos de pólen com 
ornamentação metarreticulada-equinada. A maioria dos caracteres analisados por Tellería \& Daners (2003) foi observada para as espécies estudadas, exceto o metarretículo.

Rajukar et al. (2011) analisando I. triloba, descreveram os grãos de pólen em oblato-suboblatos, pantoporados, com poros distribuídos de forma equidistante tetragonal, equinados, espinhos bulbosos, metarreticulados, microrreticulados-microequinados, estando estes dados discordantes dos aqui apresentados.

\section{Turbina Raf.}

\section{Turbina cordata (Choisy) D.F. Austin \& Staples} Figuras 31-34

Grãos de pólen mônades, grandes, esferoidais, apolares; pantoporados, ca. 29 poros circulares, com membrana apertural granulada. Exina tectada, equinada, perfurada, granulada. Espinhos coniformes, ca. 68 , com ápice pontiagudo, base larga e lados retos, localizados sobre região da sexina mais espessa que a região adjacente, raros espinhos bifurcados. Nexina mais espessa que a sexina.

Material examinado: BRASIL. BAhIA: Caetité, Brejinho das Ametistas, 18-III-2008, Vasconcelos et al. 318 (HUNEB, SP).

Os dados aqui apresentados para Turbina, principalmente quanto ao tipo apertural e ornamentação da exina, estão em consonância com os encontrados na literatura para o gênero (Pedraza 1983, PalaciosChávez et al. 1991, Araújo et al. 2000, Vital et al. 2008).

Sob MEV, foram observadas perfurações e grânulos distribuídos esparsamente sobre a superfície do grão de pólen (figura 32), além de orbículos e retículo com lumens heterogêneos localizados na base dos espinhos (figura 33).

A presença de microrretículo foi descrita por Pedraza (1983) para a espécie Turbina corymbosa (L.) Raf.. Palacios-Chávez et al. (1991) observaram também espinhos cônicos ou ampulhiformes, algumas vezes bífidos no ápice. Na espécie aqui estudada foram também observados espinhos com ápice bifurcado (figura 34).

Tipo II. Grãos de pólen 3-6- colpados, microequinados, granulados

Tribo Merremieae Austin

Merremia Dennst. ex Endl.

\section{Merremia aegyptia (L.) Urb.}

Figuras 35-38

Grãos de pólen mônades, grandes, isopolares, prolatos, amb (sub)circular; 3-colpados, com colpos longos e largos de extremidades arredondadas. Exina tectada, granulada, com grânulos distribuídos densamente por toda superfície do grão de pólen; columelas delgadas e longas; sexina mais espessa que a nexina.

Material examinado: BRASIL. BAHIA: Caetité, Brejinho das Ametistas, 29-IV-2008, Vasconcelos et al. 67 (HUNEB, SP).

\section{Merremia cissoides (Lam.) Hallier f.}

Figuras 39-42

Grãos de pólen mônades, grandes, isopolares, prolato-esferoidais, amb circular; 3(4)- zonocolpados e 6-pantocolpados. Exina semitectada, microrreticulada, granulada, com grânulos heterogêneos em diâmetro e tamanho, distribuídos densamente por toda superfície do grão de pólen; columelas longas e estreitas; sexina mais espessa que a nexina.

Material examinado: BRASIL. BAHIA: Caetité, Brejinho das Ametistas, 5-V-2009, Vasconcelos et al. 243 (HUNEB, SP).

\section{Merremia digitata (Spreng.) Hallier f.}

Figuras 43-45

Grãos de pólen mônades, grandes, isopolares, subprolatos, amb (sub)circular; 3-colpados a 6-pantocolpados, com colpos longos de contorno irregular e extremidades arredondadas. Exina tectada, granulada, com grânulos distribuídos densamente por toda superfície do grão; columelas longas e delgadas regularmente distribuídas por toda superfície do grão; sexina mais espessa que a nexina.

Material examinado: BRASIL. BAHIA: Caetité, Brejinho das Ametistas, 18-III-2008, Vasconcelos et al. 50 (HUNEB).

\section{Merremia macrocalyx (Ruiz \& Pav.) O'Donell} Figuras 46-47

Grãos de pólen mônades, grandes, isopolares, prolato-esferoidais, amb (sub)circular; 3-colpados, com colpos longos e largos de extremidades afiladas. Exina tectada e granulada, sob ML; tectado-perfurada, microequinada, sob MEV, com microespinhos distribuídos de forma heterogênea por toda superfície do grão. Columelas longas e delgadas; sexina mais espessa que a nexina. 
Material examinado: BRASIL. BAHIA: Caetité, Brejinho das Ametistas, 18-III-2008, Vasconcelos et al. 47 (HUNEB, SP).

Os dados aqui apresentados são concordantes com a literatura para a maioria das características polínicas analisadas (Laguardia 1961, Sengupta 1972, Ferguson et al. 1977, Palacios-Chávez et al. 1991, Araújo et al. 2000, Tellería \& Daners 2003, Leite et al. 2005, Vital et al. 2008).

Os grãos de pólen apresentaram tamanho grande em todas as espécies analisadas. Observou-se uma variação quanto à forma dos grãos de pólen de prolatoesferoidal a prolato (tabela 3 ).

O tipo apertural 3-colpado foi predominante no gênero, no entanto foram observados grãos de pólen 6-pantocolpados em M. cissoides (figura 42) e $M$. digitata. Há também referência na literatura para grãos de pólen 4-colpados em $M$. dissecta e M. macrocalyx (Laguardia 1961).

Araújo et al. (2000) observaram grãos de pólen 6(-78) colpados para $M$. cissoides. No espécime aqui analisado os grãos de pólen apresentaram-se 3(4)-zonocolpados a 6-pantocolpados. Ferguson et al. (1977) descreveram grãos de pólen 5-zonoaperturados, 9-12 pantocolpados, 12-pantocolpados e até pantoporados.

A ocorrência de grãos de pólen operculados para a espécie $M$. cissoides foi registrada por Leite et al. (2005), no entanto, essa estrutura não foi observada em nenhuma das espécies aqui analisadas.

Sob ML, os grãos de pólen do gênero Merremia apresentaram-se granulados; e, sob MEV, foi possível observar a presença de perfurações e microespinhos na espécie M. macrocalyx (figura 46 e 47). Palacios-Chávez et al. (1991) referfiram-se à presença de verrugas para os grãos de pólen de $M$. cissoides e $M$. tuberosa, tais elementos de ornamentação não foram aqui observados.

Sengupta (1972) caracterizou os grãos de pólen das espécies M. chryseides Hallier f. e M. emergencinata Hallier f. como tricolpados, granulados e perfurados na região da membrana apertural, e para a espécie M. umbellata Hallier, 6-colpados, reticulados. Os dados apresentados pela autora são concordantes para a maioria das características das espécies do gênero analisadas aqui, contudo não foi observado retículo nos grãos de pólen das espécies aqui analisadas.

As descrições palinológicas apresentadas por Leite et al. (2005) para as espécies de Merremia são concordantes para a maioria das espécies aqui analisadas; no entanto a espécie $M$. macrocalyx aqui analisada difere-se por possuir grãos de pólen prolatoesferoidais, perfurados (figuras 46 e 47).
De acordo com Vital et al. (2008), sob MEV, os grãos de pólen da espécie $M$. cissoides revelaram-se 3(-4)-colpados, suboblatos, médios, psilados, microespiculado-perfurados e com columelas delgadas ramificadas distalmente. Esta mesma espécie foi descrita no presente estudo, e as características encontradas são discordantes para a maioria dessas, exceto quanto ao tipo apertural.

Quanto às variações no tipo apertural, foram observadas aberturas com número variando de três a mais de 100, alongadas (colpos) e circulares (poros), localizadas apenas na região equatorial do grão (zonoaperturados) ou por todo grão (pantoaperturados).

Foi observada uma variação na morfologia dos espinhos nos grãos de pólen das espécies dos gêneros Ipomoea e Turbina: a) bulbosos, com ápice arredondado e lados côncavos (I. hederifolia, I. incarnata); b) mamilóides, com base larga e ápice arredondado (I. amnicola, I. tiloba); c) coniformes, com ápice arredondado e lados côncavos (I. procumbens, I. rosea, I. rupestris e I. subincana); d) coniformes, com ápice agudo e lados planos ( $I$. bahiensis e I. subtomentosa); e) coniformes, com ápice arredondado e lados retos (T. cordata) (tabela 1).

Através dos resultados aqui apresentados constatou-se que as tribos analisadas são distintas palinologicamente, principalmente quanto ao tipo apertural e ornamentação da exina. A morfologia polínica das tribos aqui analisadas corrobora o posicionamento dos táxons propostos por Stefanović et al. (2003), através de resultados da filogenia molecular.

\section{Agradecimentos}

As Autoras agradecem aos curadores dos herbários citados, por consentir acesso aos materiais estudados; ao Laboratório de Micromorfologia Vegetal (UEFS) em especial ao Dr. Paulino Pereira Oliveira, pela captura das imagens do MEV; à UNEB e FAPESB, pelas bolsas de iniciação científica concedida à primeira Autora.

\section{Literatura citada}

Andrade, T.A.P. \& Miranda, M.M.B. 1986. Contribuição ao conhecimento do gênero Ipomoea (Convolvulaceae) através da morfologia do pólen. Ciência Agronômica-17: 43-48.

Araújo, R.C.M.S., Leite, K.R.B. \& Santos, F.A.R. 2000. Morfologia polínica das Convolvulaceae da BahiaBrasil. Geociências 5: 208-211.

Erdtman, G. 1952. Pollen morphology and plant taxonomy: angiosperms. Alquist \& Wiksell, Stockholm.

Erdtman, G. 1960. The acetolysis method. A revised description. Svensk Botanisk Tidskrift 54: 561-564. 
Ferguson, I.K., Verdcourt, B. \& Poole, M.M. 1977. Pollen morphology in the genera Merremia and Operculina (Convolvulaceae) and its taxonomic significance. Kew Bulletin, 31: 763-773.

Hallier, H.J.G. 1893. Versuch einer natürlichen Gliederung der Convolvulaceae. Botanical Journal Arboretum 16: 479-591.

Hanks, S. \& Fryxell, P.A. 1979. Palynological studies of Gaya and Herissantia (Malvaceae). American Journal of Botany, 66: 494-501.

Hoen, P.P. \& Punt, W. 1989. Pollen morphology of the tribe Dorstenieae (Moraceae). Review of Palaeobotany and Palynology, 57: 187-220.

Hsiao, L.C. \& Kuoh, C.S. 1995. Pollen morphology of the Ipomea (Convolvulaceae) in Taiwan. Taiwania 40: 229-316.

Judd, W.S., Campbell, C.S., Kellogg, E.A., Stevens, P.F. \& Donoghue, M.J. 2009. Plant systematics: a phylogenetic approach. 3 ed. Sinauer Associates, Sunderland.

Junqueira, M.E.R. \& Simão-Bianchini, R. 2006. O gênero Evolvulus L. (Convolvulaceae) no município de Morro do Chapéu, BA, Brasil. Acta Botanica Brasilica 20: 157-172.

Laguardia, A.M. 1961. Morfologia del grano de pollen de algumas Convolvulaceas uruguayas. Boletim Sociedad Argentina Botánica 9: 187-197.

Leite, K.R.B., Simão-Bianchini, R. \& Santos, F.A.R. 2005. Morfologia polínica de espécies do gênero Merremia Dennst. (Convolvulaceae) ocorrentes no Estado da Bahia, Brasil. Acta Botanica Brasilica 19: 313-321.

Lewis, W.H. \& Oliver, R.L. 1965. Realignment of Calystegia and Convolvulus (Convolvulaceae). Annals of the Missouri Botanical Garden 52: 217-222.

Machado, I.C.S. \& Melhem, T.S. 1987. Morfologia Polínica de Ipomoea hederifolia L. e Ipomoea quamoclit L. (Convolvulaceae). Hoehnea 14: 25-30.

Manos, P.S., Miller, R.E. \& Wilkin P. 2001. Phylogenetic analysis of Ipomoea, Argyreia, Stictocardia, and Turbina suggests a generalized model of morphological evolution in morning glories. Systematic Botany 6: 585-602.

McDonald, J.A. \& Mabry, T.J. 1992. Phylogenetic systematics of New World Ipomoea (Convolvulaceae). Plant Systematics and Evolution, 180: 243-259.

Melhem, T.S. \& Corrêa, A.M.S. 1987. Flora polínica da Reserva do Parque Estadual das Fontes do Ipiranga (São Paulo, Brasil) - Família 137-Convolvulaceae. Hoehnea 14: $15-24$.

Miller, R.E., Rausher, M.D. \& Manos, P.S. 1999. Phylogenetic systematics of Ipomoea (Convolvulaceae) based on ITS, and waxy sequences. Systematic Botany 24: 209-227.

Palacios-Chávez, R., Ludlow-Wiechers, B. \& Villanueva, R.G. 1991. Flora palinologica de la reserva de la biosfera de Sian Ka'an Quintana Roo, Mexico. Centro de Investigações de Quintana Roo, Chetumal, pp. 65-66.
Pedraza, R.A. 1983. Estudio palinológico de la família Convolvulaceae de México I. Generos Ipomoea L. y Turbina Raf. (Por extenso) Biotica; 8: 387-411.

Punt, W., Hoen, P.P., Blackmore, S., Nilsson, S. \& Le Thomas, A. 2007. Glossary of pollen and spores terminology. Review of Paleobotany and Palynology 143: 1-81.

Queiroz, L.P., Conceicao, A. \& Giulietti, A.M. 2006. Nordeste Semi-árido: caracterização geral e lista das fanerógamas. In: Giulietti, A.M. \& Queiroz, L.P. (orgs.). Instituto do Milênio do Semi-árido: diversidade e caracterização das fanerógamas do semi-árido brasileiro. Vol. 1. APNE, Recife. pp. 15-364.

Rajukar, T.V., Tidke, J.A \& Patil, G.V. 2011. Studies on pollen morphology of Ipomoea species (Convolvulaceae). Research in Plant Biology 1: 41-47.

Salgado-Labouriau, M.L. 1973. Contribuição à palinologia do Cerrado. Academia de Ciências, Rio de Janeiro.

Sengupta, S. 1972. On the pollen morphology of Convolvulaceae with special reference to taxonomy. Review of Paleobotany and Palynology 13: 157-212.

Simão-Bianchini, R., Ferreira, P.P.A. \& Pastore, M. 2014. Convolvulaceae. In: Lista de Espécies da Flora do Brasil. Disponível em http://floradobrasil.jbrj.gov.br (acesso em 13-VII-2014).

Souza, V.C. \& Lorenzi, H. 2012. Botânica Sistemática: Guia ilustrado para identificação das famílias de fanerógamas nativas e exóticas no Brasil, baseado em APG II. 3 ed. Instituto Plantarum de Estudos da Flora Ltda, Nova Odessa.

Stefanović, S., Krueger, L. \& Olmstead, R.G. 2002. Monophyly the Convolvulaceae and circumscription of their major lineages based on DNA sequences of multiple chloroplast loci. American Journal of Botany 89: 1510-1522.

Stefanović, S., Austin, D.F. \& Olmstead, R.G. 2003. Classification of Convolvulaceae: A Phylogenetic Approach. Systematic Botany, 28: 791-806.

Stefanović, S. \& Olmstead, R.G. 2004. Testing the phylogenetic position of a parasitic plant (Cuscuta, Convolvulaceae, Asteridae): Bayesian inference and the parametric bootstrap on data drawn from three genomes. Systematic Biology 53: 384-399.

SEI - Superintendência de Estudos Econômicos e Socias da Bahia. 2012. Atributos climáticos do Estado da Bahia. Disponível em http://www.sei.ba.gov.br (acesso em 13-VII-2014).

Tellería, M.C. \& Daners, G. 2003. Pollen types in Southern New World Convolvulaceae and their taxonomic significance. Plant Systematics and Evolution 243: 99-118.

Thiers, B. 2012 [continuously updated]. Index Herbariorum: A global directory of public herbaria and associated staff. Disponível em http://sweetgum.nybg.org/ih/ (acesso em 13-VII-2014).

Vij, S.P. \& Sachdeva, V.P. 1974. Pollen grain studies in some Indian Convolvulaceae. Journal of Palynology 10: $132-344$.

Vital, M.T.A.B., Santos, F.A.R. \& Alves, M. 2008. Diversidade Palinológica das Convolvulaceae do Parque Nacional do Catimbau, Buíque, PE, Brasil. Acta Botanica Brasilica-22: 1163-1171. 